\title{
The prevalence and clinical characteristics of nonradiographic axial spondyloarthritis among patients with inflammatory back pain in rheumatology practices: a multinational, multicenter study
}

Ruben Burgos-Vargas', James Cheng-Chung Wei ${ }^{2,3,4^{*}}$, Mahboob U. Rahman ${ }^{5,6}$, Nurullah Akkoc ${ }^{7}$, Syed Atiqul Haq ${ }^{8}$, Mohammed Hammoudeh ${ }^{9}$, Ehab Mahgoub ${ }^{6}$, Ena Singh ${ }^{6}$, Lyndon John Llamado ${ }^{10}$, Khalid Shirazy ${ }^{11}$,

Sameer Kotak ${ }^{12}$, Constance Hammond ${ }^{6}$, Ron Pedersen ${ }^{6}$, Qi Shen ${ }^{6}$ and Bonnie Vlahos ${ }^{6}$

\begin{abstract}
Background: Patients with ankylosing spondylitis (AS), who by definition have radiographic sacroiliitis, typically experience symptoms for a decade or more before being diagnosed. Yet, even patients without radiographic sacroiliitis (i.e., nonradiographic axial spondyloarthritis [nr-axSpA]) report a significant disease burden. The primary objective of this study was to estimate the prevalence and clinical characteristics of nr-axSpA among patients with inflammatory back pain (IBP) in rheumatology clinics in a number of countries across the world. A secondary objective was to estimate the prevalence of IBP among patients with chronic low back pain (CLBP).

Methods: Data were collected from 51 rheumatology outpatient clinics in 19 countries in Latin America, Africa, Europe, and Asia. As consecutive patients with CLBP $(N=2517)$ were seen by physicians at the sites, their clinical histories were evaluated to determine whether they met the new Assessment of SpondyloArthritis international Society criteria for IBP. For those who did, their available clinical history (e.g., family history, C-reactive protein [CRP] levels) was documented in a case report form to establish whether they met criteria for nr-axSpA, AS, or other IBP. Patients diagnosed with nr-axSpA or AS completed patient-reported outcome measures to assess disease activity and functional limitations.
\end{abstract}

Results: A total of 2517 patients with CLBP were identified across all sites. Of these, 974 (38.70\%) fulfilled the criteria for IBP. Among IBP patients, $29.10 \%$ met criteria for nr-axSpA, and $53.72 \%$ met criteria for AS. The prevalence of nr-axSpA varied significantly by region $(p<0.05)$, with the highest prevalence reported in Asia (36. $46 \%)$ and the lowest reported in Africa (16.02\%). Patients with nr-axSpA reported mean \pm SD Ankylosing Spondylitis Disease Activity Scores based on erythrocyte sedimentation rate and CRP of $2.62 \pm 1.17$ and $2.52 \pm 1.21$, respectively, indicating high levels of disease activity (patients with AS reported corresponding scores of $2.97 \pm 1.13$ and $2.93 \pm 1.18$ ). Similarly, the overall Bath Ankylosing Spondylitis Disease Activity Index score of $4.03 \pm 2.23$ for patients with nr-axSpA (4.56 \pm 2.17 for patients with AS) suggested suboptimal disease control.

(Continued on next page)

\footnotetext{
*Correspondence: jccwei@gmail.com

${ }^{2}$ Division of Allergy, Immunology and Rheumatology, Chung Shan Medical

University Hospital, No. 110, Sec. 1, Jianguo N. Road, South District, Taichung City 40201, Taiwan

${ }^{3}$ Institute of Medicine, Chung Shan Medical University, Taichung City, Taiwan

Full list of author information is available at the end of the article
} 
(Continued from previous page)

Conclusions: These results suggest that, in the centers that participated in the study, $29 \%$ of patients with IBP met the criteria for nr-axSpA and $39 \%$ of patients with CLBP had IBP. The disease burden in nr-axSpA is substantial and similar to that of AS, with both groups of patients experiencing inadequate disease control. These findings suggest the need for early detection of nr-axSpA and initiation of available treatment options to slow disease progression and improve patient well-being.

Keywords: Nonradiographic axial SpA, Ankylosing spondylitis, Prevalence, Inflammatory low back pain, Chronic low back pain

\section{Background}

Spondyloarthritis $(\mathrm{SpA})$ is a constellation of chronic inflammatory conditions that includes ankylosing spondylitis (AS), reactive arthritis, enteropathic arthritis, and psoriatic arthritis, among others [1]. Collectively, the prevalence of SpA varies between $0.5 \%$ and $2 \%$, making it approximately as common as rheumatoid arthritis [1]. On the basis of their clinical presentation, patients with SpA can be categorized as having axial SpA, in which the spine is predominantly affected, or peripheral SpA, in which the extremities are predominantly affected $[2,3]$. According to the 2009 criteria of the Assessment of SpondyloArthritis international Society (ASAS), axial SpA is further categorized into nonradiographic axial SpA (nraxSpA) and AS, in which the major distinguishing feature is the presence (for AS) or absence (for $\mathrm{nr}$-axSpA) of radiographic sacroiliitis $[2,3]$.

Approximately $10 \%$ of patients with nr-axSpA develop AS within 2 years and $60 \%$ develop AS within 10 years [4]. Although patients with nr-axSpA may have inflammation detectable by magnetic resonance imaging $[5,6]$, early detection of axial SpA poses a major challenge to many physicians $[2,3]$. Indeed, patients may experience symptoms for a decade or more before receiving a diagnosis [1]. Patients with axial SpA also report a number of impairments in physical functioning and spinal mobility, experience high rates of disability, and contribute to high societal costs [4]. Timely identification of axial SpA may potentially lead to earlier and more effective intervention to delay disease progression [5].

The majority of axial SpA studies have been conducted in Europe, the United States, and Mexico, with information extremely limited in the emerging countries of Latin America, Africa, Central and Eastern Europe, and Asia. The general population prevalence of axial $\mathrm{SpA}$ in Europe has been estimated to be between $0.08 \%$ (France) and $0.49 \%$ (Turkey) [6]. The prevalence is slightly higher in the Americas, with researchers in Mexico and the United States reporting rates of $0.60 \%$ and $0.90-1.40 \%$, respectively $[6,7]$.

Many of the studies cited above have been focused on AS or axial SpA, leading to a lack of epidemiological and clinical data specific to nr-axSpA. Indeed, even the proportion of axial SpA patients with $\mathrm{nr}-\mathrm{axSpA}$ is unknown, as estimates vary considerably, ranging from $23 \%$ to $80 \%$ in a recent review of patients with axial SpA [4]. In part, this is due to different methods of assessment and the fact that these studies were not specifically designed to follow patients with undifferentiated SpA and nr-axSpA [4].

The lack of data on nr-axSpA and AS is even more pronounced in emerging countries in Latin America, Europe, Africa, and Asia. The primary objective of this study was to provide prevalence estimates on the presence of nr-axSpA among patients with inflammatory back pain (IBP) in rheumatology clinics across a number of emerging countries. In this study, we also sought to describe the clinical characteristics associated with both $n r-a x S p A$ and AS. A secondary objective was to estimate the prevalence of IBP among patients with chronic low back pain (CLBP), given that IBP represents an increasingly important part of identifying patients with axial SpA $[2,3]$.

\section{Methods}

\section{Study design}

A noninterventional, cross-sectional study was conducted to estimate the prevalence of nr-axSpA among patients with IBP in 51 rheumatology outpatient clinics from 19 countries in Latin America (Colombia, Costa Rica, Mexico, and Peru), Europe inclusive of western Asia (Hungary, Israel, Kazakhstan, Poland, Romania, Russia, and Turkey), Africa (Algeria, Morocco, and South Africa), and Asia focused on southern and eastern Asia (Bangladesh, China, India, Malaysia, and Taiwan). Patient recruitment took place from January through December 2014. The protocol and study materials received institutional review board approval at each participating site; the specific sites are listed in the Acknowledgements section.

Consecutive patients with CLBP were seen by participating physicians at the study sites and were evaluated clinically to determine whether they met the criteria for IBP. Patients who met 2009 ASAS criteria for IBP had their clinical histories further evaluated to determine their eligibility for the medical record abstraction portion of this 
study. The inclusion criteria were age $\geq 18$ years, CLBP $\geq 3$ months, and four of five of the following parameters: age of onset $<40$ years, insidious onset, improvement with exercise, no improvement with rest, and pain at night. The exclusion criteria were noninflammatory back pain, a condition that could mimic IBP (e.g., fibromyalgia), the presence of a neuropathic component, unexplained weight loss of $>10 \mathrm{~kg}$ within the past 6 months, persistent fever, urinary incontinence or retention, saddle anesthesia, decreased anal sphincter tone or fecal incontinence, bilateral lower extremity weakness or numbness, or progressive neurologic deficit.

For patients who met the appropriate inclusion criteria and provided written informed consent, a medical record abstraction using a case report form (CRF) was performed to determine whether the patients met the criteria for AS, nr-axSpA, or other forms of IBP ("other IBP" hereafter) based on ASAS criteria for axial SpA and the Modified New York (Modified NY) criteria for AS (Fig. 1). More specifically, patients who did not meet ASAS criteria were classified as having other IBP. Patients who met ASAS criteria for axial SpA but did not meet Modified NY criteria were classified as having
nr-axSpA. Patients who met both ASAS criteria for axial SpA and Modified NY criteria were classified as having AS.

Patients who were diagnosed with AS or nr-axSpA were provided with a brief survey to evaluate their patient-reported outcomes (PROs). It is important to note that diagnosed refers to the physician's classification of that patient as indicated in the medical record. It is not known what information was used to make this assessment. The classification of patients based on ASAS criteria for axial SpA and Modified NY criteria for AS, as described above, was an analytical exercise performed by the authors after data collection; it was not conducted in real time as patients were enrolled into the study. As a result, the study depended upon the physician's classification (referred hereafter as diagnosis to distinguish the methods) in order to identify patients eligible to receive the survey, even if this differed from our methods of classification using the ASAS criteria for axial SpA and the Modified NY criteria for AS. This survey was completed entirely by the patient in the waiting room to avoid any influence from the investigator. At the end of subject recruitment, all completed materials were

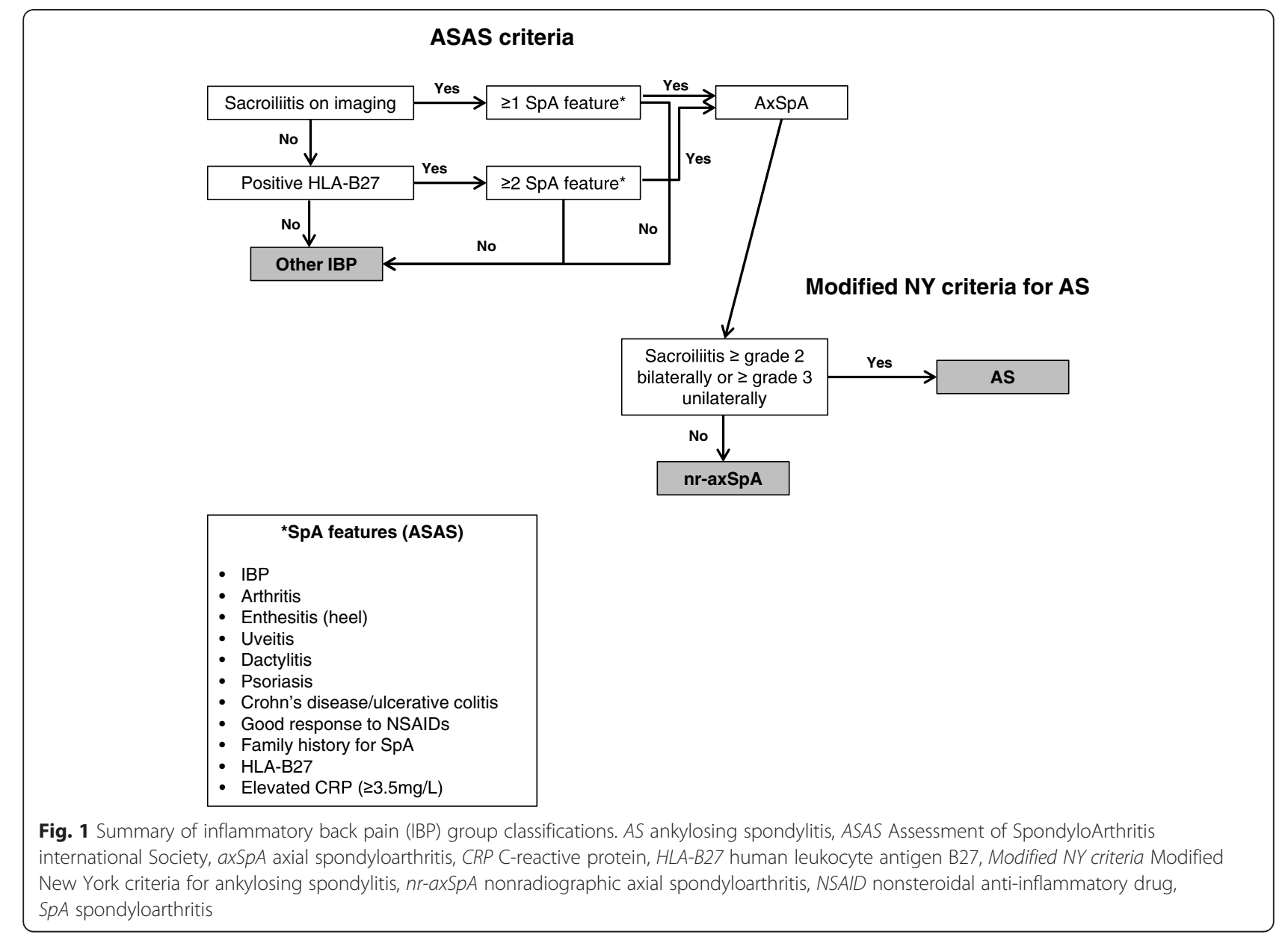


collected on-site and checked for completion, with the exception of the patient questionnaire, which remained confidential.

\section{Measures}

The CRF assessed information on each patient's demographics (age, sex, race/ethnicity), general health history (body mass index [BMI], years of experienced CLBP), and disease history (human leukocyte antigen B27 [HLA-B27] test results, C-reactive protein [CRP] results, erythrocyte sedimentation rate [ESR] results, family history, nonsteroidal anti-inflammatory drug [NSAID] response). The patient survey included the Ankylosing Spondylitis Disease Activity Score (ASDAS; both ESR and CRP versions), Bath Ankylosing Spondylitis Disease Activity Index (BASDAI), Bath Ankylosing Spondylitis Functional Index (BASFI), and Bath Ankylosing Spondylitis Metrology Index (BASMI).

\section{Statistical analysis}

The analysis of the primary objectives (prevalence and clinical characteristics of nr-axSpA) was focused on patients with IBP who met the inclusion or exclusion criteria described above. The analysis of the secondary objective (prevalence of IBP among patients with CLBP) was focused on all patients with CLBP. Frequencies, percentages, and $95 \%$ CIs were reported for binary and/or categorical variables. Counts, means, and SDs were reported for continuous variables. Statistical differences across geographical regions were analyzed using chisquare tests and one-way analysis of variance for categorical and continuous variables, respectively.

\section{Results}

Prevalence of nr-axSpA overall, by region, and by sex A total of 2517 patients with CLBP were identified across all sites (Fig. 2). Of these, 974 (38.70\%) fulfilled the criteria for IBP and were advanced to the CRF portion of the study for assessment of IBP group status (i.e., nr-axSpA, AS, or other IBP). Overall, $29.10 \%$ (95 \% CI 26.15-32.05 \%) of patients with IBP met the criteria for nr-axSpA (Table 1). The prevalence of AS among patients with IBP was $53.72 \%$ (95\% CI 50.48-56.96\%). The prevalence of nr-axSpA varied significantly by region $(p<0.05)$, with the highest prevalence reported in Asia (36.46 \%, 95 \% CI 31.64-41.28 \%) and the lowest reported in Africa (16.02 \%, $95 \%$ CI 11.00$21.04 \%)$. The prevalence of $\mathrm{nr}$-axSpA was similar among males (28.74 \%, $95 \%$ CI 25.07-32.41 \%) and females (29.75\%, 95 \% CI 24.77-34.74 \%) with IBP.

\section{Demographic characteristics of patients with nr-axSpA}

Patients with nr-axSpA had a mean age of 34.75 years (SD 10.03); $36.47 \%$ were female, and $55.64 \%$ were white (Table 2). These figures contrasted with patients with AS, who had a mean age of 39.03 years (SD 11.38); $28.72 \%$ were female, and $68.23 \%$ were white. Minimal regional differences were observed with respect to the demographic characteristics of patients with nr-axSpA (Table 3). Patients with nr-axSpA were oldest in Africa (36.67 years) and youngest in Asia (33.24 years) $(p<0.05)$; however, no differences in sex, BMI, years since CLBP presentation, or age of IBP onset were observed across regions.

Clinical characteristics of patients with nr-axSpA

Patients with nr-axSpA experienced CLBP for $6.32 \pm$ 7.61 years (compared with 10.91 years for patients with

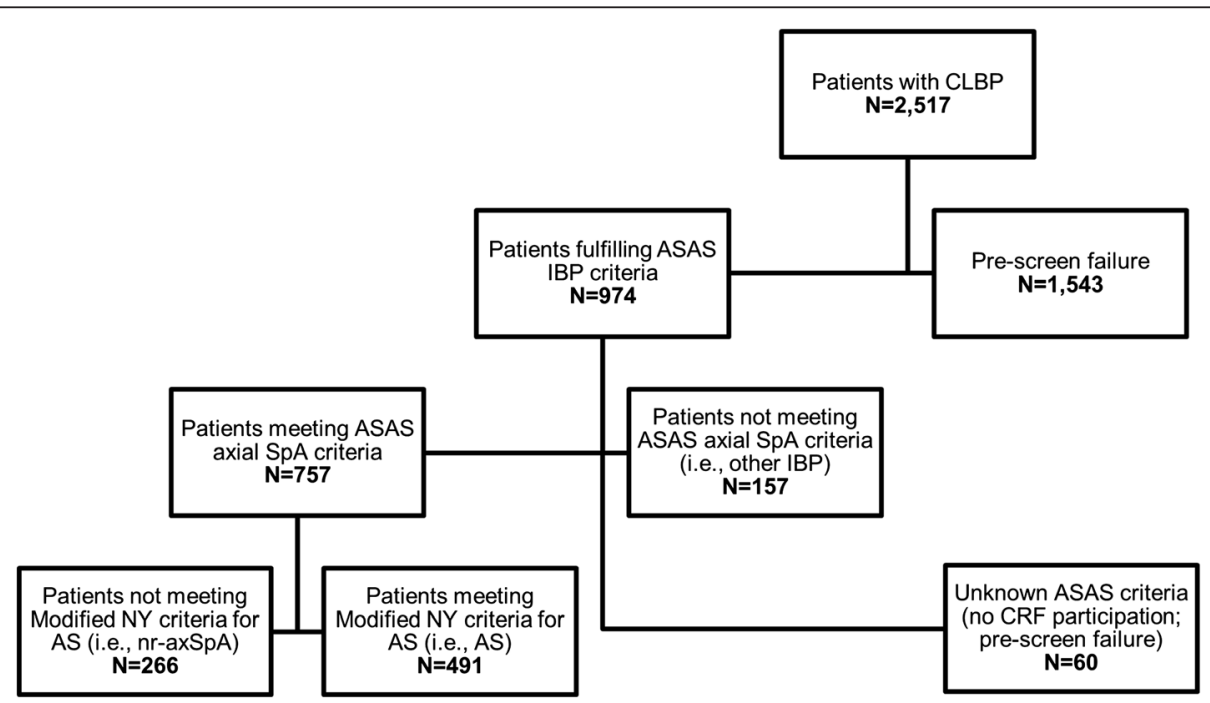

Fig. 2 Study flowchart. AS ankylosing spondylitis, ASAS Assessment of SpondyloArthritis international Society, CLBP chronic low back pain, CRF case report form, IBP inflammatory back pain, Modified NY criteria Modified New York criteria for ankylosing spondylitis, nr-axSpA nonradiographic axial spondyloarthritis, SpA spondyloarthritis 
Table 1 Prevalence of nonradiographic axial spondyloarthritis among patients with inflammatory back pain across geographic regions

\begin{tabular}{|c|c|c|c|c|c|c|}
\hline & Total & Latin America & Africa & Europe & Asia & $p$ Value \\
\hline \multicolumn{7}{|l|}{ Overall sample } \\
\hline Number of patients & 914 & 26 & 206 & 298 & 384 & \multirow{3}{*}{$<0.001$} \\
\hline nr-axSpA, n (\%) & 266 (29.10 \%) & $5(19.23 \%)$ & $33(16.02 \%)$ & 88 (29.53 \%) & 140 (36.46 \%) & \\
\hline $95 \%$ Cl & $(26.15-32.05)$ & $(4.05-34.41)$ & $(11.00-21.04)$ & $(24.34-34.72)$ & (31.64-41.28) & \\
\hline \multicolumn{7}{|l|}{ Among males } \\
\hline Number of patients & 588 & 12 & 116 & 204 & 256 & \multirow{3}{*}{$<0.001$} \\
\hline nr-axSpA, n (\%) & 169 (28.74 \%) & $4(33.33 \%)$ & 18 (15.52 \%) & 57 (27.94 \%) & 90 (35.16 \%) & \\
\hline $95 \% \mathrm{Cl}$ & $(25.07-32.41)$ & $(6.58-60.08)$ & $(8.91-22.13)$ & $(21.77-34.12)$ & $(29.29-41.02)$ & \\
\hline \multicolumn{7}{|l|}{ Among females } \\
\hline Number of patients & 326 & 14 & 90 & 94 & 128 & \multirow{3}{*}{$<0.001$} \\
\hline nr-axSpA, n (\%) & $97(29.75 \%)$ & $1(7.14 \%)$ & 15 (16.67 \%) & 31 (32.98 \%) & $50(39.06 \%)$ & \\
\hline $95 \% \mathrm{Cl}$ & $(24.77-34.74)$ & $(0.00-20.70)$ & $(8.93-24.41)$ & $(23.42-42.53)$ & $(30.57-47.56)$ & \\
\hline
\end{tabular}

$n$ r-axSpA nonradiographic axial spondyloarthritis

The $p$ values represent the omnibus statistical comparison of percentages across geographic regions

AS) (Table 2). HLA-B27 test results were available for $71.05 \%$ of those with nr-axSpA, and $82.78 \%$ of them had a positive test result (Table 4). Proportions of $68.14 \%$ and $37.30 \%$ of patients with nr-axSpA had elevated CRP and ESR values, respectively. For context, proportions of $77.20 \%$ and $48.92 \%$ of patients with AS had elevated CRP and ESR values, respectively.

Several clinical characteristics varied across regions among those with nr-axSpA (Table 5). Patients in Europe were the most likely to have a positive HLA-B27 test result $(84.85 \%)$, and patients in Asia were the least likely $(62.24 \%)(p<0.05)$. Patients in Asia were the most likely to have an elevated ESR value (48.89\%), and patients in Europe were the least likely $(20.48 \%)(p<0.05)$. No differences in family history or NSAID response were observed.

\section{Delay from IBP and CLBP to nr-axSpA or AS diagnosis}

For patients who received a diagnosis of nr-axSpA, there was a mean delay of $5.21 \pm 7.69$ years between the presentation of IBP and diagnosis (Table 4). There was a mean delay of $6.48 \pm 8.53$ years between the presentation of IBP and diagnosis for patients with AS.

\section{Patient-reported outcomes in nr-axSpA and AS}

The mean disease activity levels for patients with $\mathrm{nr}$ axSpA were $2.62 \pm 1.17$ and $2.52 \pm 1.21$ for the ESR and CRP versions of the ASDAS, respectively, suggesting a high level of disease activity (i.e., $\geq 2.1$ ) (Table 6). The mean overall BASDAI score was $4.03 \pm 2.32$ for patients with nr-axSpA, indicating a suboptimal level of disease control. Finally, BASFI score $(3.20 \pm 2.47)$ and BASMI scores (11-point version $2.41 \pm 1.54$, 3-point version $1.62 \pm 1.51$, linear function version $3.71 \pm 2.77$ ) indicated a significant burden for patients with nr-axSpA and were relatively comparable to BASFI score $(4.09 \pm 2.59)$ and BASMI scores (11-point version 4.09 \pm 2.06 , 3-point version $3.40 \pm 2.25$, linear function version $4.77 \pm 2.38$ ) for patients with AS. No differences in PRO measures were observed across regions, with the exception of the 3-point BASMI version (Africa $=2.59 \pm 1.52$, Europe $=1.46 \pm 1.53$, Asia $=1.30 \pm 1.36 ; p<0.05)$.

\section{Discussion}

In this study, $39 \%$ of patients referred to rheumatology clinics with CLBP met the ASAS criteria for IBP. Further, $29 \%$ of patients with IBP met the criteria for nr-axSpA. The proportion of axial SpA patients with nr-axSpA was within the range (23-80\%) reported in the literature $[4,8]$, though on the lower end of prior estimates.

Our data suggest a higher percentage of males among patients with nr-axSpA (64\%) relative to the percentages in other published noninterventional studies (34-50 \%) $[9,10]$ and most clinical trials (48-64 \%) [11-16]. There were a number of methodological differences across these studies (e.g., inclusion and exclusion criteria, country), but it is unclear which of these factors would help to explain the differences in results. Further research is necessary.

We found that patients with nr-axSpA were the youngest, and they experienced CLBP for the shortest duration at slightly over 6 years compared with nearly 11 years for patients with AS. Although no age differences were found in past literature reviews between patients with nr-axSpA and those with AS [4, 8], several prior studies have found a longer symptom duration for patients with AS $[4-8,10,17,18]$. This is to be 
Table 2 Demographic characteristics of nonradiographic axial spondyloarthritis, ankylosing spondylitis, and other inflammatory back pain patients

\begin{tabular}{|c|c|c|c|c|c|}
\hline & Total $(N=914)$ & $n r-a x S p A(n=266)$ & AS $(n=491)$ & Other IBP $(n=157)$ & $p$ Value \\
\hline Sex & & & & & $<0.001$ \\
\hline Male, $n(\%)$ & $588(64.33 \%)$ & 169 (63.53 \%) & $350(71.28 \%)$ & $69(43.95 \%)$ & \\
\hline $95 \% \mathrm{Cl}$ & $(61.22-67.44)$ & $(57.74-69.33)$ & $(67.27-75.29)$ & $(36.17-51.73)$ & \\
\hline Female, $n(\%)$ & 326 (35.67 \%) & $97(36.47 \%)$ & $141(28.72 \%)$ & $88(56.05 \%)$ & \\
\hline $95 \% \mathrm{Cl}$ & (32.56-38.78) & $(30.67-42.26)$ & $(24.71-32.73)$ & $(48.27-63.83)$ & \\
\hline Sex & & & & & $<0.001$ \\
\hline Male, $n$ (row \%) & $588(100.00 \%)$ & 169 (28.75 \%) & 350 (59.52 \%) & $69(11.73 \%)$ & \\
\hline $95 \% \mathrm{Cl}$ & & $(25.08-32.41)$ & $(55.54-63.50)$ & $(9.13-14.34)$ & \\
\hline Female, $n$ (row \%) & $326(100.00 \%)$ & $97(29.75 \%)$ & 141 (43.25 \%) & $88(26.99 \%)$ & \\
\hline $95 \% \mathrm{Cl}$ & & $(24.78-34.73)$ & $(37.86-48.64)$ & $(22.17-31.82)$ & \\
\hline Age, years, mean $\pm S D$ & $38.68 \pm 12.02$ & $34.75 \pm 10.03$ & $39.03 \pm 11.38$ & $44.26 \pm 14.48$ & $<0.001$ \\
\hline Race/ethnicity & & & & & $<0.001$ \\
\hline White, $n$ (\%) & 596 (65.21 \%) & 148 (55.64 \%) & 335 (68.23 \%) & 113 (71.97 \%) & \\
\hline $95 \% \mathrm{Cl}$ & $(62.11-68.30)$ & $(49.66-61.62)$ & $(64.10-72.35)$ & $(64.94-79.01)$ & \\
\hline Asian, $n(\%)$ & 116 (12.69 \%) & $55(20.68 \%)$ & $55(11.20 \%)$ & $6(3.82 \%)$ & \\
\hline $95 \% \mathrm{Cl}$ & $(10.53-14.85)$ & $(15.80-25.55)$ & $(8.41-14.00)$ & $(0.82-6.83)$ & \\
\hline Black, $n$ (\%) & $12(1.31 \%)$ & $2(0.75 \%)$ & $2(0.41 \%)$ & $8(5.10 \%)$ & \\
\hline $95 \% \mathrm{Cl}$ & $(0.57-2.05)$ & $(0.00-1.79)$ & $(0.00-0.97)$ & $(1.65-8.54)$ & \\
\hline Unknown, $n$ (\%) & 190 (20.79 \%) & $61(22.93 \%)$ & $99(20.16 \%)$ & $30(19.11 \%)$ & \\
\hline $95 \% \mathrm{Cl}$ & $(18.15-23.42)$ & $(17.87-27.99)$ & $(16.61-23.72)$ & $(12.95-25.27)$ & \\
\hline BMI category & & & & & 0.024 \\
\hline Underweight, n (\%) & $55(6.02 \%)$ & 12 (4.51\%) & $38(7.74 \%)$ & $5(3.18 \%)$ & \\
\hline $95 \% \mathrm{Cl}$ & $(4.47-7.56)$ & $(2.01-7.01)$ & $(5.37-10.11)$ & $(0.43-5.94)$ & \\
\hline Normal weight, $n(\%)$ & $455(49.78 \%)$ & $150(56.39 \%)$ & $236(48.07 \%)$ & $69(43.95 \%)$ & \\
\hline $95 \% \mathrm{Cl}$ & $(46.53-53.03)$ & $(50.42-62.36)$ & $(43.64-52.49)$ & $(36.17-51.73)$ & \\
\hline Overweight, $n$ (\%) & $279(30.53 \%)$ & $78(29.32 \%)$ & $146(29.74 \%)$ & $55(35.03 \%)$ & \\
\hline $95 \% \mathrm{Cl}$ & $(27.53-33.52)$ & $(23.84-34.8)$ & $(25.68-33.79)$ & $(27.56-42.51)$ & \\
\hline Obese, $n(\%)$ & $121(13.24 \%)$ & $24(9.02 \%)$ & $70(14.26 \%)$ & $27(17.20 \%)$ & \\
\hline $95 \% \mathrm{Cl}$ & $(11.04-15.44)$ & $(5.57-12.47)$ & $(11.16-17.36)$ & $(11.28-23.11)$ & \\
\hline Unknown, n (\%) & $4(0.44 \%)$ & $2(0.75 \%)$ & $1(0.20 \%)$ & $1(0.64 \%)$ & \\
\hline $95 \% \mathrm{Cl}$ & $(0.01-0.87)$ & $(0.00-1.79)$ & $(0.00-0.60)$ & $(0.00-1.88)$ & \\
\hline Years since CLBP presentation & & & & & $<0.001$ \\
\hline Number of patients & 808 & 232 & 435 & 141 & \\
\hline Mean $\pm S D$, years & $9.09 \pm 9.07$ & $6.32 \pm 7.61$ & $10.91 \pm 9.37$ & $8.05 \pm 9.10$ & \\
\hline Age of IBP onset & & & & & $<0.001$ \\
\hline Number of patients & 908 & 264 & 488 & 156 & \\
\hline Mean $\pm S D$, years & $28.8 \pm 9.7$ & $27.8 \pm 7.3$ & $27.0 \pm 7.7$ & $36.2 \pm 14.2$ & \\
\hline
\end{tabular}

Abbreviations: $A S$ ankylosing spondylitis, $B M I$ body mass index, CLBP chronic low back pain, CRF case report form, IBP inflammatory back pain, $n r-a x S p A$ nonradiographic axial spondyloarthritis

Broad race categories (white vs. black vs. Asian vs. unknown) were created on the basis of physician-reported patient ethnicity: white $=$ Indian, Indo-Aryan,

Dravidian, Bengali, Arab, Iranian, white, Jewish, Azeri, Mestizo, Amerindian, Berber; black = black, mulatto, mulato, zambo, black African, colored; Asian = Han

Chinese, non-Han Chinese, Taiwanese, Chinese, aborigine, Malay, indigenous, mongoloid, Asian; unknown = other or missing

The $p$ values represent the omnibus statistical comparison of percentages (or means) across IBP groups based on the chi-square (or $F$-test) values

"Other IBP" refers to patients who did not meet the Assessment of SpondyloArthritis international Society classification criteria for axial spondyloarthritis 
Table 3 Demographic characteristics of patients with nonradiographic axial spondyloarthritis across geographic regions

\begin{tabular}{|c|c|c|c|c|}
\hline & Africa $(n=33)$ & Europe $(n=88)$ & Asia $(n=140)$ & $p$ Value \\
\hline Sex & & & & 0.609 \\
\hline Male, $n(\%)$ & $18(54.55 \%)$ & $57(64.77 \%)$ & $90(64.29 \%)$ & \\
\hline $95 \% \mathrm{Cl}$ & $(37.45-71.64)$ & $(54.73-74.82)$ & $(56.30-72.27)$ & \\
\hline Female (\%) & $15(45.45 \%)$ & $31(35.23 \%)$ & $50(35.71 \%)$ & \\
\hline $95 \% \mathrm{Cl}$ & $(28.36-62.55)$ & $(25.18-45.27)$ & $(27.73-43.70)$ & \\
\hline Age, years mean $\pm S D$ & $36.67 \pm 10.73$ & $36.02 \pm 10.56$ & $33.24 \pm 9.26$ & 0.035 \\
\hline BMI category & & & & 0.21 \\
\hline Underweight, n (\%) & $1(3.03 \%)$ & $4(4.55 \%)$ & $7(5.00 \%)$ & \\
\hline $95 \% \mathrm{Cl}$ & $(0.00-8.92)$ & $(0.17-8.93)$ & $(1.37-8.63)$ & \\
\hline Normal weight, $n(\%)$ & $16(48.48 \%)$ & $51(57.95 \%)$ & $81(57.86 \%)$ & \\
\hline $95 \% \mathrm{Cl}$ & (31.32-65.65) & $(47.57-68.34)$ & (49.62-66.09) & \\
\hline Overweight, $n$ (\%) & $13(39.39 \%)$ & 19 (21.59\%) & $44(31.43 \%)$ & \\
\hline $95 \% \mathrm{Cl}$ & $(22.61-56.17)$ & $(12.94-30.24)$ & $(23.69-39.17)$ & \\
\hline Obese, $n(\%)$ & $2(6.06 \%)$ & $14(15.91 \%)$ & 7 (5.00 \%) & \\
\hline $95 \% \mathrm{Cl}$ & $(0.00-14.25)$ & $(8.22-23.6)$ & $(1.37-8.63)$ & \\
\hline Unknown, n (\%) & $1(3.03 \%)$ & $0(0.00 \%)$ & 1 (0.71\%) & \\
\hline $95 \% \mathrm{Cl}$ & $(0.00-8.92)$ & - & $(0.00-2.12)$ & \\
\hline Years since CLBP presentation & & & & 0.462 \\
\hline Number of patients & 29 & 74 & 124 & \\
\hline Mean $\pm S D$, years & $8.02 \pm 10.01$ & $6.68 \pm 9.33$ & $5.67 \pm 5.70$ & \\
\hline Age of IBP onset & & & & 0.115 \\
\hline Number of patients & 33 & 87 & 139 & \\
\hline Mean $\pm S D$, years & $28.4 \pm 8.7$ & $28.3 \pm 6.5$ & $27.1 \pm 7.3$ & \\
\hline
\end{tabular}

$B M I$ body mass index, CLBP chronic low back pain

The $p$ values represent the omnibus statistical comparison of percentages (or means) across regions based on the chi-square (or $F$-test) values

expected, given that nr-axSpA and AS likely represent a progression in the spectrum of the same disease.

Among patients who had been diagnosed with nraxSpA, there was a delay of approximately 5 years between presentation of IBP and diagnosis. This finding was consistent with the study by Poddubnyy and colleagues, who which also found a gap of slightly more than 5 years between back pain and the assessment of nr-axSpA [17]. However, it should be noted that many patients who met the criteria for nr-axSpA were not diagnosed even after this period of several years, reinforcing the importance of increasing the awareness of, and adherence to, ASAS classification criteria for timely diagnosis and initiation of treatment.

Among those with HLA-B27 test results, $83 \%$ of the patients with nr-axSpA had positive results. This finding is consistent with what was summarized by Boonen et al. [4] and reported directly in two recent noninterventional studies (73\% in a study by Poddubnyy and colleagues [11] and $86 \%$ in a study by Kiltz and colleagues [18]. Over two-thirds (68\%) of patients with nr-axSpA had elevated CRP values $(\geq 3.5 \mathrm{mg} / \mathrm{L})$, which was nearly as high as the percentage of patients with AS who had elevated CRP values (77\%).

Data derived from the patient surveys demonstrated a high level of disease activity and a suboptimal level of disease control, as assessed using the ASDAS and BASDAI, respectively, for patients with nr-axSpA. It is important to note that even patients with nr-axSpA [19], who are in an earlier phase in the course of axial SpA, exhibited a significant burden that was comparable to that of patients with AS. BASDAI scores in our study were lower than those reported in a review of clinical trial results of biologic treatments [8], suggesting a less severe patient-reported burden in this real-world patient population. The levels of functional impairment (BASFI) and limitations (BASMI) were comparable to those reported for clinical trial populations [4]. Given the early age of onset for nr-axSpA, these impairment data suggest that patients can experience a substantial level of burden for many years. This further illustrates the importance of identifying patients early in order to slow disease progression. 
Table 4 Clinical characteristics and HLA-B27 test results of patients with nonradiographic axial spondyloarthritis, ankylosing spondylitis, and other inflammatory back pain

\begin{tabular}{|c|c|c|c|c|c|}
\hline & Total $(N=914)$ & $n r-a x S p A(n=266)$ & AS $(n=491)$ & Other IBP $(n=157)$ & $p$ Value \\
\hline HLA-B27 test results (when available) & & & & & $<0.001$ \\
\hline Positive, $n(\%)$ & 397 (72.98 \%) & $135(71.43 \%)$ & $250(82.78 \%)$ & $12(22.64 \%)$ & \\
\hline Negative, $n(\%)$ & $147(27.02 \%)$ & $54(28.57 \%)$ & $52(17.22 \%)$ & $41(77.36 \%)$ & \\
\hline Years from IBP to SpA diagnosis & & & & & 0.747 \\
\hline Number of patients & 179 & 98 & 27 & 54 & \\
\hline Mean $\pm S D$, years & $5.40 \pm 7.98$ & $5.21 \pm 7.69$ & $6.48 \pm 8.53$ & $5.19 \pm 8.32$ & \\
\hline Family history of SpA & & & & & $<0.001$ \\
\hline Yes, $n(\%)$ & $220(24.07 \%)$ & $70(26.32 \%)$ & $132(26.88 \%)$ & $18(11.46 \%)$ & \\
\hline No, $n(\%)$ & $650(71.12 \%)$ & $180(67.67 \%)$ & $343(69.86 \%)$ & 127 (80.89 \%) & \\
\hline Results not available, $n$ (\%) & $44(4.81 \%)$ & $16(6.02 \%)$ & $16(3.26 \%)$ & $12(7.64 \%)$ & \\
\hline Family history of SpA (excluding missing) & & & & & $<0.001$ \\
\hline Yes, $n(\%)$ & $220(25.29 \%)$ & $70(28.00 \%)$ & $132(27.79 \%)$ & $18(12.41 \%)$ & \\
\hline No, $n(\%)$ & $650(74.71 \%)$ & $180(72.00 \%)$ & $343(72.21 \%)$ & $127(87.59 \%)$ & \\
\hline NSAID response & & & & & 0.125 \\
\hline Positive, $n(\%)$ & $657(71.88 \%)$ & $183(68.80 \%)$ & 358 (72.91\%) & $116(73.89 \%)$ & \\
\hline Negative, $n(\%)$ & $231(25.27 \%)$ & $72(27.07 \%)$ & $125(25.46 \%)$ & $34(21.66 \%)$ & \\
\hline Results not available, $n(\%)$ & $26(2.84 \%)$ & $11(4.14 \%)$ & $8(1.63 \%)$ & $7(4.46 \%)$ & \\
\hline Most recent CRP value & & & & & 0.146 \\
\hline Number of patients & 767 & 226 & 421 & 120 & \\
\hline Mean $\pm S D, m g / L$ & $16.7 \pm 26.0$ & $15.8 \pm 28.2$ & $18.2 \pm 25.3$ & $13.2 \pm 23.5$ & \\
\hline Most recent CRP level & & & & & $<0.001$ \\
\hline Not elevated (<3.5 mg/L), n (\%) & $219(23.96 \%)$ & $72(27.07 \%)$ & 96 (19.55 \%) & $51(32.48 \%)$ & \\
\hline Elevated ( $\geq 3.5$ mg/L), n (\%) & $548(59.96 \%)$ & $154(57.89 \%)$ & $325(66.19 \%)$ & $69(43.95 \%)$ & \\
\hline Results not available, $n$ (\%) & $147(16.08 \%)$ & $40(15.04 \%)$ & $70(14.26 \%)$ & 37 (23.57 \%) & \\
\hline Most recent CRP level (excluding missing) & & & & & $<0.001$ \\
\hline Not elevated (<3.5 mg/L), n (\%) & $219(28.55 \%)$ & $72(31.86 \%)$ & $96(22.80 \%)$ & $51(42.50 \%)$ & \\
\hline Elevated ( $\geq 3.5 \mathrm{mg} / \mathrm{L}), n(\%)$ & $548(71.45 \%)$ & $154(68.14 \%)$ & $325(77.20 \%)$ & $69(57.50 \%)$ & \\
\hline Most recent ESR value & & & & & 0.009 \\
\hline Number of patients & 846 & 252 & 464 & 130 & \\
\hline Mean $\pm S D, m m / h$ & $29.0 \pm 23.6$ & $26.8 \pm 23.9$ & $31.2 \pm 23.6$ & $25.3 \pm 22.8$ & \\
\hline Most recent ESR level & & & & & $<0.001$ \\
\hline Not elevated (<28 mm/h), $n(\%)$ & $482(52.74 \%)$ & $158(59.40 \%)$ & $237(48.27 \%)$ & $87(55.41 \%)$ & \\
\hline Elevated ( $\geq 28 \mathrm{~mm} / \mathrm{h}), n(\%)$ & $364(39.82 \%)$ & $94(35.34 \%)$ & $227(46.23 \%)$ & $43(27.39 \%)$ & \\
\hline Results not available, $n(\%)$ & $68(7.44 \%)$ & $14(5.26 \%)$ & $27(5.50 \%)$ & $27(17.20 \%)$ & \\
\hline Most recent ESR level (excluding missing) & & & & & $<0.001$ \\
\hline Not elevated (<28 mm/h), $n$ (\%) & $482(56.97 \%)$ & $158(62.70 \%)$ & 237 (51.08 \%) & $87(66.92 \%)$ & \\
\hline Elevated ( $\geq 28 \mathrm{~mm} / \mathrm{h}), n(\%)$ & $364(43.03 \%)$ & $94(37.30 \%)$ & $227(48.92 \%)$ & $43(33.08 \%)$ & \\
\hline
\end{tabular}

Abbreviations: $A S$ ankylosing spondylitis, CRP C-reactive protein, ESR erythrocyte sedimentation rate, $H L A-B 27$ human leukocyte antigen B27, IBP inflammatory back pain, $n r$-axSpA nonradiographic axial spondyloarthritis, NSAID nonsteroidal anti-inflammatory drug, SpA spondyloarthritis

The $p$ values represent the omnibus statistical comparison of percentages (or means) across IBP groups based on the chi-square values

\section{Limitations}

Limitations of this epidemiological study include the use of a single assessment with a questionnaire and CRF that may not adequately capture a comprehensive medical history for a particular patient. It is also important to mention that this was an observational study, so not all patients had complete information available. This could have affected the classification of patients and therefore 
Table 5 Clinical characteristics and HLA-B27 test results of patients with nonradiographic axial spondyloarthritis across geographic regions

\begin{tabular}{|c|c|c|c|c|}
\hline & Africa $(n=33)$ & Europe $(n=88)$ & Asia $(n=140)$ & $p$ Value \\
\hline Laboratory-confirmed SpA (HLA-B27) & & & & 0.062 \\
\hline Positive, $n(\%)$ & $15(45.45 \%)$ & $56(63.64 \%)$ & $61(43.57 \%)$ & \\
\hline Negative, $n(\%)$ & $6(18.18 \%)$ & $10(11.36 \%)$ & $37(26.43 \%)$ & \\
\hline Results not available, $n(\%)$ & $12(36.36 \%)$ & $22(25.00 \%)$ & $42(30.00 \%)$ & \\
\hline Laboratory-confirmed SpA (excluding missing) (HLA-B27) & & & & 0.019 \\
\hline Positive, $n(\%)$ & $15(71.43 \%)$ & $56(84.85 \%)$ & $61(62.24 \%)$ & \\
\hline Negative, $n(\%)$ & $6(28.57 \%)$ & $10(15.15 \%)$ & $37(37.76 \%)$ & \\
\hline Family history of SpA & & & & 0.231 \\
\hline Yes, $n(\%)$ & $9(27.27 \%)$ & $18(20.45 \%)$ & $43(30.71 \%)$ & \\
\hline No, $n(\%)$ & $22(66.67 \%)$ & $67(76.14 \%)$ & $86(61.43 \%)$ & \\
\hline Results not available, $n$ (\%) & $2(6.06 \%)$ & $3(3.41 \%)$ & $11(7.86 \%)$ & \\
\hline Family history of SpA (excluding missing) & & & & 0.125 \\
\hline Yes, $n(\%)$ & $9(29.03 \%)$ & $18(21.18 \%)$ & $43(33.33 \%)$ & \\
\hline No, $n(\%)$ & $22(70.97 \%)$ & $67(78.82 \%)$ & $86(66.67 \%)$ & \\
\hline NSAID response & & & & 0.264 \\
\hline Positive, $n(\%)$ & $22(66.67 \%)$ & $64(72.73 \%)$ & $93(66.43 \%)$ & \\
\hline Negative, $n(\%)$ & 7 (21.21\%) & $22(25.00 \%)$ & $42(30.00 \%)$ & \\
\hline Results not available, $n(\%)$ & $4(12.12 \%)$ & $2(2.27 \%)$ & $5(3.57 \%)$ & \\
\hline Most recent CRP level & & & & 0.214 \\
\hline Not elevated (<3.5 mg/L), n (\%) & $10(30.30 \%)$ & $21(23.86 \%)$ & $37(26.43 \%)$ & \\
\hline Elevated ( $\geq 3.5 \mathrm{mg} / \mathrm{L}), n(\%)$ & $18(54.55 \%)$ & $55(62.50 \%)$ & $80(57.14 \%)$ & \\
\hline Results not available, $n(\%)$ & $5(15.15 \%)$ & $12(13.64 \%)$ & $23(16.43 \%)$ & \\
\hline Most recent CRP level (excluding missing) & & & & 0.104 \\
\hline Not elevated (<3.5 mg/L), n (\%) & $10(35.71 \%)$ & $21(27.63 \%)$ & $37(31.62 \%)$ & \\
\hline Elevated $(\geq 3.5 \mathrm{mg} / \mathrm{L}), n(\%)$ & $18(64.29 \%)$ & $55(72.37 \%)$ & $80(68.38 \%)$ & \\
\hline Most recent ESR level & & & & $<0.001$ \\
\hline Not elevated $(<28 \mathrm{~mm} / \mathrm{h}), n(\%)$ & $20(60.61 \%)$ & $66(75.00 \%)$ & $69(49.29 \%)$ & \\
\hline Elevated ( $\geq 28 \mathrm{~mm} / \mathrm{h}), n(\%)$ & $9(27.27 \%)$ & $17(19.32 \%)$ & $66(47.14 \%)$ & \\
\hline Results not available, $n$ (\%) & $4(12.12 \%)$ & $5(5.68 \%)$ & $5(3.57 \%)$ & \\
\hline Most recent ESR level (excluding missing) & & & & $<0.001$ \\
\hline Not elevated $(<28 \mathrm{~mm} / \mathrm{h}), n(\%)$ & $20(68.97 \%)$ & $66(79.52 \%)$ & $69(51.11 \%)$ & \\
\hline Elevated ( $\geq 28 \mathrm{~mm} / \mathrm{h}), n(\%)$ & $9(31.03 \%)$ & $17(20.48 \%)$ & $66(48.89 \%)$ & \\
\hline
\end{tabular}

Abbreviations: CRP C-reactive protein, ESR erythrocyte sedimentation rate, HLA-B27 human leukocyte antigen B27, NSAID nonsteroidal anti-inflammatory drug, SpA spondyloarthritis

The $p$ values represent the omnibus statistical comparison of percentages (or means) across regions based on the chi-square values

the prevalence estimates. For example, because a positive HLA-B27 test is one way to classify a patient as having nraxSpA instead of other IBP, missing HLA-B27 data would underestimate the number of nr-axSpA patients relative to other IBP patients. Another limitation was the lack of available information on the other IBP group. Although this group also had poor outcomes based on the PRO data, the explanation for this finding is unclear without knowing more about the composition of the other IBP group. Patient surveys were administered only to patients who were diagnosed with AS and nr-axSpA, so patients who were not diagnosed with either condition, even if they met the appropriate classification criteria, did not provide PRO data. The external validity of the study is dependent on the extent to which patients at the selected rheumatology practices are representative of all IBP patients in these countries. Because these sites were selected for being major centers for the treatment of SpA, it is possible the patients who are managed by these sites are fundamentally different (e.g., more severe disease). 
Table 6 Clinical outcomes and patient-reported outcome measures for patients with nonradiographic axial spondyloarthritis, ankylosing spondylitis, and other inflammatory back pain

\begin{tabular}{|c|c|c|c|c|c|}
\hline & Total $(N=686)$ & nr-axSpA $(N=188)$ & AS $(N=413)$ & Other IBP $(N=85)$ & $p$ Value \\
\hline ASDAS score (ESR) & & & & & 0.003 \\
\hline Number of patients & 619 & 167 & 378 & 74 & \\
\hline Mean \pm SD & $2.87 \pm 1.14$ & $2.62 \pm 1.17$ & $2.97 \pm 1.13$ & $2.92 \pm 1.01$ & \\
\hline ASDAS score (CRP) & & & & & 0.002 \\
\hline Number of patients & 559 & 149 & 346 & 64 & \\
\hline Mean \pm SD & $2.81 \pm 1.19$ & $2.52 \pm 1.21$ & $2.93 \pm 1.18$ & $2.81 \pm 1.17$ & \\
\hline BASDAI & & & & & 0.010 \\
\hline Number of patients & 681 & 186 & 412 & 83 & \\
\hline Mean \pm SD & $4.44 \pm 2.24$ & $4.03 \pm 2.32$ & $4.56 \pm 2.17$ & $4.77 \pm 2.29$ & \\
\hline BASFI & & & & & $<0.001$ \\
\hline Number of patients & 683 & 187 & 411 & 85 & \\
\hline Mean \pm SD & $4.09 \pm 2.59$ & $3.20 \pm 2.47$ & $4.43 \pm 2.57$ & $4.38 \pm 2.49$ & \\
\hline BASMI (11-point) & & & & & $<0.001$ \\
\hline Number of patients & 575 & 154 & 353 & 68 & \\
\hline Mean \pm SD & $3.55 \pm 2.03$ & $2.41 \pm 1.54$ & $4.09 \pm 2.06$ & $3.33 \pm 1.75$ & \\
\hline BASMI (3-point) & & & & & $<0.001$ \\
\hline Number of patients & 564 & 146 & 347 & 71 & \\
\hline Mean \pm SD & $2.83 \pm 2.19$ & $1.62 \pm 1.51$ & $3.40 \pm 2.25$ & $2.52 \pm 2.03$ & \\
\hline BASMI (linear function) & & & & & $<0.001$ \\
\hline Number of patients & 686 & 188 & 413 & 85 & \\
\hline Mean \pm SD & $4.44 \pm 2.55$ & $3.71 \pm 2.77$ & $4.77 \pm 2.38$ & $4.47 \pm 2.50$ & \\
\hline
\end{tabular}

Abbreviation: AS ankylosing spondylitis, ASDAS Ankylosing Spondylitis Disease Activity Score, BASDAl Bath Ankylosing Spondylitis Disease Activity Index, BASFI Bath Ankylosing Spondylitis Functional Index, BASMI Bath Ankylosing Spondylitis Metrology Index, CRP C-reactive protein, ESR erythrocyte sedimentation rate, IBP inflammatory back pain, $n r-a x S p A$ nonradiographic axial spondyloarthritis

The $p$ values represent the omnibus statistical comparison of percentages (or means) across IBP groups based on the $F$-test values

\section{Conclusions}

The results of the present study suggest that approximately one-third of patients with IBP meet ASAS criteria for nr-axSpA. Patients with nr-axSpA, as compared with patients with AS, tend to be younger and experience symptoms for a shorter time before diagnosis. The PRO data suggest that the overall disease burden in nraxSpA is substantial and similar to that in AS, with both groups of patients experiencing inadequate disease control. These findings show the continued need for early diagnosis of nr-axSpA across Latin America, Europe, Africa, and Asia. These findings also emphasize the importance of early initiation of available treatment options to slow disease progression and improve patient wellbeing in these patients' most productive years of life.

\section{Abbreviations}

AS, ankylosing spondylitis; ASAS, Assessment of SpondyloArthritis international Society; ASDAS, Ankylosing Spondylitis Disease Activity Score; BASDAl, Bath Ankylosing Spondylitis Disease Activity Index; BASFI, Bath Ankylosing Spondylitis Functional Index; BASMI, Bath Ankylosing Spondylitis Metrology Index; BMI, body mass index; CLBP, chronic low back pain; CRF, case report form; CRP, C-reactive protein; ESR, erythrocyte sedimentation rate; HLA-B27, human leukocyte antigen B27; IBP, inflammatory back pain;
Modified NY criteria, Modified New York criteria for ankylosing spondylitis; nr-axSpA, nonradiographic axial spondyloarthritis; NSAID, nonsteroidal antiinflammatory drug; PRO, patient-reported outcome; SpA, spondyloarthritis95 \% Cl

\section{Acknowledgements}

The authors acknowledge the contributions of the various principal investigators at each site who assisted with the data collection: Drs. Bao, Wang, and Wu (China); Dr. Tsai (Taiwan); Drs. Hussein and Lay (Malaysia); Drs. Islam and Rahman (Bangladesh); Drs. Pulukool, Rajshekhar, Sarkar, and Mouli (India); Drs. Itzhak and Levi (Israel); Drs. Kenar, Ozbek, and Karabulut (Turkey); Drs. Ancuta and Opris (Romania); Drs. Elonakov, Kamalova, Lapshina, Dubinina, and Savinkova (Russia); Drs. Świerkot, Chlebicki, Klama, Krezelok, and Zielinski (Poland); Drs. Széntó, Geher, Keszthelyi, Nagy, and Varga (Hungary); Dr. Tleukulov (Kazakhstan); Drs. Casasola, Flores, Ureña, Fajardo, Martinez (Mexico); Drs. Coto and Mendez (Costa Rica); Dr. Parra (Colombia); Dr. Rojo (Peru); Drs. Djoudi, Ladjouze, Dahou, Benzaoui, and Boudersa (Algeria); Drs. Najia, Toufik, Imane, and Radouane (Morocco); and Drs. Reuter and Plooy (South Africa)

The authors also acknowledge the various institutional review boards and ethics committees of the participating institutions: Shanghai Changhai Hospital Ethics Committee (China), Chung Shan Medical Hospital (Taiwan), Kaohsiung Medical University (Taiwan), Chung-Ho Memorial Hospital (Taiwan), Medical Research \& Ethics Committee (Malaysia), Bangabandhu Sheikh Mujib Medical University (Bangladesh), Christian Medical College (India), Nizam's Institute of Medical Sciences (India), Institutional Ethics Committee of Human Research at Medical College (India), KIMS Foundation and Research Center (India), Bnai Zion Medical Center (Israel), Meir Medical Center (Israel), Dokuz Eylul University (Turkey), Warsaw University of Medicine (Poland), University of Szeged Albert Szent-Gyorgyi Clinical Center (Hungary), 
Creimed (Colombia), Institutional Ethics Committee of the University of San Martin de Porres (Peru), Ethics Committee for Biomedical Research (Central Ethics Committee of Morocco), National Commission for Personal Data Protection (Central Ethics Committee of Morocco), Medicines Control Council (Central Ethics Committee of South Africa), and Human Research Ethics Committee of Wits Donald Gordon Medical Hospital (South Africa). The authors also acknowledge Valérie Auclair, PhD, Hélène Kuyas, Xavier Guillaume, MS, MBA, and Geneviève Bonnelye, MS, for their contributions to the study design and data collection, as well as Marco DiBonaventura, PhD, who oversaw the statistical analysis and contributed to the interpretation of the data. Dr. Auclair, Ms. Kuyas, Mr. Guillaume, Ms. Bonnelye, and Dr. DiBonaventura were all full-time employees of Kantar Health at the time of the study, which received funding from Pfizer. Medical writing support was provided by Marco DiBonaventura, PhD, at Kantar Health and was funded by Pfizer. Finally, the authors acknowledge the participation of all the patients included in the study.

\section{Authors' contributions}

RBV, JCCW, MUR, NA, SAH, MH, EM, ES, LLL, KS, SK, CH, RP, QS, and BV participated in the study design. MUR, EM, BV, CH, and QS participated in the study coordination and data collection. BV, CH, RP, and QS led the interpretation of the study results with assistance from the remaining authors. All authors helped to draft the manuscript, and all authors read and approved the final manuscript.

\section{Competing interests}

RBV, JCCW, NA, SAH, and MH were paid to participate as site investigators for the study. This study was sponsored by Pfizer. MUR, EM, ES, LLL, SK, CH, $\mathrm{RP}, \mathrm{QS}$, and BV were all full-time employees of Pfizer at the time of this study. The authors declare that they have no nonfinancial competing interests.

\section{Author details}

'Department of Rheumatology, General Hospital of Mexico, Mexico City, Mexico. ${ }^{2}$ Division of Allergy, Immunology and Rheumatology, Chung Shan Medical University Hospital, No. 110, Sec. 1, Jianguo N. Road, South District, Taichung City 40201, Taiwan. ${ }^{3}$ Institute of Medicine, Chung Shan Medical University, Taichung City, Taiwan. ${ }^{4}$ Graduate Institute of Integrated Medicine, China Medical University, Taichung City, Taiwan. ${ }^{5}$ University of Pennsylvania, Philadelphia, PA, USA. ${ }^{6}$ Pfizer, Collegeville, PA, USA. 'Dokuz Eylül University, İmir, Turkey. ${ }^{8}$ Bangabandhu Sheikh Mujib Medical University, Dhaka, Bangladesh. ${ }^{9}$ Hamad Hospital, Doha, Qatar. ${ }^{10}$ Pfizer Asia Pacific Region, Makati, Philippines. " Pfizer Africa and Middle East Region, Dubai, UAE.

${ }^{12}$ Pfizer, New York, NY, USA.

Received: 9 January 2016 Accepted: 19 May 2016

Published online: 07 June 2016

\section{References}

1. Reveille JD. Spondylarthritis (Spondylarthropathy). 2012. http://www. rheumatology.org/I-Am-A/Patient-Caregiver/Diseases-Conditions/ Spondyloarthritis. Accessed 2 Jun 2015.

2. Rudwaleit M, Landewé R, van der Heijde D, Listing J, Brandt J, Braun J, et al. The development of Assessment of SpondyloArthritis international Society classification criteria for axial spondyloarthritis (part I): classification of paper patients by expert opinion including uncertainty appraisal. Ann Rheum Dis. 2009;68:770-6.

3. Rudwaleit M, van der Heijde D, Landewé R, Listing J, Akkoc N, Brandt J, et al. The development of Assessment of SpondyloArthritis international Society classification criteria for axial spondyloarthritis (part II): validation and final selection. Ann Rheum Dis. 2009;68:777-83.

4. Boonen A, Sieper J, van der Heijde D, Dougados M, Bukowski JF, Valluri S, et al. The burden of non-radiographic axial spondyloarthritis. Semin Arthritis Rheum. 2015:44:556-62.

5. Huerta-Sil G, Casasola-Vargas JC, Londoño JD, Rivas-Ruíz R, Chávez J, Pacheco-Tena $C$, et al. Low grade radiographic sacroiliitis as prognostic factor in patients with undifferentiated spondyloarthritis fulfilling diagnostic criteria for ankylosing spondylitis throughout follow up. Ann Rheum Dis. 2006;65:642-6.

6. Stolwijk C, Boonen A, van Tubergen A, Reveille JD. Epidemiology of spondyloarthritis. Rheum Dis Clin North Am. 2012;38:441-76.
7. Peláez-Ballestas I, Navarro-Zarza JE, Julian B, Lopez A, Flores-Camacho R, Casasola-Vargas JC, et al. A community-based study on the prevalence of spondyloarthritis and inflammatory back pain in Mexicans. J Clin Rheumatol. 2013;19:57-61.

8. Sieper J, van der Heijde D. Review: Nonradiographic axial spondyloarthritis: new definition of an old disease? Arthritis Rheum. 2013;65:543-51.

9. Dougados M, d'Agostino MA, Benessiano J, Berenbaum F, Breban M, Claudepierre $P$, et al. The DESIR cohort: a 10-year follow-up of early inflammatory back pain in France: study design and baseline characteristics of the 708 recruited patients. Joint Bone Spine. 2011;78:598-603.

10. Poddubnyy D, Rudwaleit M, Haibel H, Listing J, Märker-Hermann E, Zeidler H, et al. Rates and predictors of radiographic sacroiliitis progression over 2 years in patients with axial spondyloarthritis. Ann Rheum Dis. 2011;70:1369-74.

11. Althoff $C E$, Sieper J, Song $H$, Haibel H, Weiß A, Diekhoff T, et al. Active inflammation and structural change in early active axial spondyloarthritis as detected by whole-body MRI. Ann Rheum Dis. 2013;72:967-73.

12. Sieper J, van der Heijde D, Dougados M, Mease PJ, Maksymowych WP, Brown MA, et al. Efficacy and safety of adalimumab in patients with nonradiographic axial spondyloarthritis: results of a randomized placebocontrolled trial (ABILITY-1). Ann Rheum Dis. 2013;72:815-22.

13. van der Heijde D, Dijkmans B, Geusens P, Sieper J, DeWoody K, Williamson $P$, et al. Efficacy and safety of infliximab in patients with ankylosing spondylitis: results of a randomized, placebo-controlled trial (ASSERT). Arthritis Rheum. 2005;52:582-91.

14. Ciurea A, Scherer A, Exer P, Bernhard J, Dudler J, Beyeler B, et al. Tumor necrosis factor a inhibition in radiographic and nonradiographic axial spondyloarthritis: results from a large observational cohort. Arthritis Rheum. 2013;65:3096-106.

15. Dougados M, van der Heijde D, Sieper J, Braun J, Maksymowych WP, Citera $\mathrm{G}$, et al. Symptomatic efficacy of etanercept and its effects on objective signs of inflammation in early nonradiographic axial spondyloarthritis: a multicenter, randomized, double-blind, placebo-controlled trial. Arthritis Rheumatol. 2014;66:2091-102.

16. Landewé R, Braun J, Deodhar A, Dougados M, Maksymowych WP, Mease PJ, et al. Efficacy of certolizumab pegol on signs and symptoms of axial spondyloarthritis including ankylosing spondylitis: 24-week results of a double-blind randomised placebo-controlled phase 3 study. Ann Rheum Dis. 2014;73:39-47.

17. Poddubnyy D, Brandt $H$, Vahldiek J, Spiller I, Song $I H$, Rudwaleit $M$, et al. The frequency of non-radiographic axial spondyloarthritis in relation to symptom duration in patients referred because of chronic back pain: results from the Berlin early spondyloarthritis clinic. Ann Rheum Dis. 2012;71:1998-2001.

18. Kiltz U, Baraliakos $X$, Karakostas $P$, Igelmann $M$, Kalthoff $L$, Klink $C$, et al. Do patients with non-radiographic axial spondylarthritis differ from patients with ankylosing spondylitis? Arthritis Care Res. 2012;64:1415-22.

19. Machado P, Landewé R, Lie E, Kvien TK, Braun J, Baker D, et al. Ankylosing Spondylitis Disease Activity Score (ASDAS): defining cut-off levels for disease activity states and improvement scores. Ann Rheum Dis. 2011;70:47-53.

\section{Submit your next manuscript to BioMed Central and we will help you at every step:}

- We accept pre-submission inquiries

- Our selector tool helps you to find the most relevant journal

- We provide round the clock customer support

- Convenient online submission

- Thorough peer review

- Inclusion in PubMed and all major indexing services

- Maximum visibility for your research

Submit your manuscript at www.biomedcentral.com/submit
) Biomed Central 